\title{
Promoter hypermethylation-induced transcriptional down-regulation of the gene MYCT1 in laryngeal squamous cell carcinoma
}

Min Yang ${ }^{1,2+}$, Wei Li ${ }^{1,3 \dagger}$, Yi-Ying Liu', Shuang Fu', Guang-Bin Qiu', Kai-Lai Sun ${ }^{1}$ and Wei-Neng Fu*

\begin{abstract}
Background: MYCT1, previously named MTLC, is a novel candidate tumor suppressor gene. MYCT1 was cloned from laryngeal squamous cell cancer (LSCC) and has been found to be down-regulated in LSCC; however, the regulatory details have not been fully elucidated.

Methods: Here, we sought to investigate the methylation status of the CpG islands of MYCT1 and mRNA levels by bisulfite-specific PCR (BSP) based on sequencing restriction enzyme digestion, reverse transcription and real-time quantitative polymerase chain reaction (RQ-PCR). The function of specific sites in the proximal promoter of MYCT1 in LSCC was measured by transient transfection, luciferase assays, electrophoretic mobility shift assay (EMSA) and chromatin immunoprecipitation assay (ChIP).

Results: The results suggested hypermethylation of $12 \mathrm{CpG}$ sites of the promoter in both laryngeal cancer tissues and the laryngeal cancer line Hep-2 cell. The hypermethylation of the site CGCG (-695 to -692), which has been identified as the c-Myc binding site, was identified in laryngeal cancer tissues (59/73) compared to paired mucosa (13/73); in addition, statistical analysis revealed that the methylation status of this site significantly correlated with cancer cell differentiation $(p<0.01)$. The mRNA level of MYCT1 increased in Hep-2 cells treated with 5-aza-C $(p<0.01)$. The luciferase activity from mutant transfectants $p G L 3-M Y C T 1 m(-852 /+12$, mut-695-C $>A$, mut-693-C > G) was significantly reduced compared with the wild type pGL3-MYCT1 (-852/+12), while the luciferase activity from wild transfectants pGL3-MYCT1 (-852/+12) rose after 5-aza treatment in Hep-2 cells. Finally, EMSA and ChIP confirmed that the methylation of the CGCG (-695 to -692) site prevented c-Myc from binding of the site and demethylation treatment of the $5^{\prime}$ flanking region of MYCT1 by 5 -aza induced the increased occupation of the core promoter by c-Myc $(p<0.01)$.
\end{abstract}

Conclusion: In summary, this study concluded that hypermethylation contributed to the transcriptional down-regulation of MYCT1 and could inhibit cancer cell differentiation in LSCC. DNA methylation of the CGCG site (-695 to -692) of MYCT1 altered the promoter activity by interfering with its binding to c-Myc in LSCC. Epigenetic therapy of reactivating MYCT1 by 5-aza should be further evaluated in clinical trails of LSCC.

Keywords: Hypermethylation, MYCT1, Laryngeal squamous cell carcinoma

\footnotetext{
* Correspondence: wnfu@mail.cmu.edu.cn

'Equal contributors

'Department of Medical Genetics, China Medical University, Shenyang

110001 , P.R. China

Full list of author information is available at the end of the article
} 


\section{Background}

Laryngeal cancer is the second most common respiratory system cancer, and the overall incidence of laryngeal cancer in individuals between 0-44 years old in China has shown a highly increasing trend in the recent decades [1,2]. Greater than $90 \%$ of laryngeal cancer has been pathologically identified as laryngeal squamous cell carcinoma (LSCC) [3]. Currently, the primary treatment for LSCC is surgery followed by radiotherapy [4]. Total laryngectomy, the most common type of surgery used in advanced cases, seriously impairs laryngeal function and the quality of life of LSCC patients [5]. Therefore, understanding the epigenetic pathways involved in the pathogenesis of LSCC is still urgently needed to improve the chemotherapeutic and diagnostic molecular biomarkers to objectively appraise LSCC; in addition, a better understanding of these pathways will improve treatment and increase the survival rate of LSCC patients [6].

MYCT1, which was previously named MTLC (c-Myc target from laryngeal cancer cells, GenBank access number AF527367), was cloned by our team in 2003. MYCT1 is located on $6 \mathrm{q} 25$ and has two exons. As a putative target of c-Myc, MYCT1 is expressed in the nuclei of human hepatocellular carcinoma cells, while a wide distribution of MYCT1 has been demonstrated in various tissues [7]. The closest homolog, mouse MT-MC1 (c-Myc target in myeloid cells-1), can regulate many c-Myc target genes in myeloid cells, which implies that like MT-MC1, MYCT1 may participate in the regulation of cell function through the c-Myc signaling network [8-10]. We previously found that MYCT1 is downregulated in gastric cancer [11]. Recently, Fu et al. in our group found that MYCT1 is transcribed at a low level in LSCC. These authors also confirmed that the transcriptional start site of MYCT1 is located 140 bp upstream of the ATG start codon using 5' rapid amplification of cDNA ends (RACE)(GenBank access number GU997693.1) and that c-Myc can regulate the promoter activity of MYCT1 by specifically binding to the E-box elements within the -886 to -655 bp region [12].

c-Myc is a transcription factor that forms heterodimers with the protein Max and binds gene promoters by recognizing the DNA sequence CACGTG, which is called a canonical E-box [13]. c-Myc can also bind several other non-canonical E-box motifs, such as CATGTG, CATGCG, CACGCG, CACGAG, CGCGAG and CAACGTG [14-16]. Understanding the regulation of the expression of c-Myc target genes is an important step for understanding their biological functions in both physiological and pathological contexts [17]. Several studies have demonstrated that methylation of the CpG dinucleotide within the E-box can prevent the access of c-Myc to target gene promoters in vivo $[18,19]$. This idea has been further reinforced by a study that has shown that c-Myc does not bind to EGFR in HL-60 cells due to methylation of the E-box sites, whereas 5-aza-2'-deoxycytidine (5-aza), a demethylating agent that blocks cellular DNA methyltransferase activity, can restore the binding of c-Myc to the E-box and increase gene transcription [20]. Based on these premises, a causal link exists between methylation of the E-box and c-Myc binding and transcription.

We speculate that MYCT1 might act as a tumor suppressor gene (TSG) in LSCC carcinogenesis and metastasis. The mechanism of abnormal expression of TSGs in the process of malignant transformation primarily involves point mutations, loss of heterozygosity, and epigenetic modifications (such as hypermethylation) [21]. Specifically, aberrant methylation of CpG islands in gene-specific promoter regions can affect transcriptional function and has been found to be related to human diseases [22]. In this study, we sought to investigate the methylation status of $\mathrm{CpG}$ islands, mRNA levels and the function of specific promoter sites of MYCT1 in LSCC.

\section{Materials and methods \\ Cell culture}

The human laryngeal carcinoma cell line Hep-2 was obtained from the Cell Biology Institute of Shanghai, Chinese Academy of Science. The cells were grown in RPMI-1640 with $10 \% \mathrm{FBS}$, penicillin $(100 \mathrm{U} / \mathrm{ml})$ and streptomycin $(100 \mu \mathrm{g} / \mathrm{ml})$ at $37{ }^{\circ} \mathrm{C}$ in a $5 \% \mathrm{CO}_{2}$ humidified atmosphere.

\section{Samples and tissue DNA extraction}

Seventy-three patients who were diagnosed with resectable LSCC tumors at the ENT Department of the 463 Hospital of PLA between 2002 and 2005 were enrolled in the study. The LSCC tissues were pathologically confirmed according to the UICC classification (TNM 2002). Patients who had undergone radiotherapy or chemotherapy prior to surgery were excluded from the study. All of the patients provided written informed consent, and approval for the study was received from the Ethics Committee of China Medical University. All specimens, including cancerous and paired adjacent normal laryngeal tissues, were obtained fresh during the surgery and stored at $-80{ }^{\circ} \mathrm{C}$. Genomic DNA from the LSCC tissues and Hep-2 cells was isolated with DNAzol reagent (Invitrogen Life Technologies, San Diego, CA). Purified DNA was concentrated by ethanol precipitation. The DNA concentration was determined using a spectrophotometer.

\section{Bisulfite modification and bisulfite-specific PCR (BSP)}

Genomic DNA from Hep-2 cells and 10 LSCC samples was randomly selected for methylation status screening. Approximately $1 \mu \mathrm{g}$ of genomic DNA was bisulfitemodified using the EZ DNA Methylation-Gold Kit ${ }^{\mathrm{TM}}$ 
(Zymo Research, Orange, CA) according to the manufacturer's recommendations. Based on the functional promoter sequence of the MYCT1 gene, the primers (F: 5'-TTAAATAGAGAAATAGATATGTTAAGAATA-3'; R: 5'-TATACAAAATTAAAAAATAAACCAC-3') used in bisulfite-specific PCR (BSP) detection were designed using MethPrimer (http://www.urogene.org/methprimer/ index.html), and the amplified fragment was $449 \mathrm{bp}$. The PCR reaction was performed in a $25 \mu$ reaction system, starting with denaturation at $94{ }^{\circ} \mathrm{C}$ for $4 \mathrm{~min}$, then 30 cycles of denaturation at $94{ }^{\circ} \mathrm{C}$ for $30 \mathrm{sec}$, annealing at $53{ }^{\circ} \mathrm{C}$ for $30 \mathrm{sec}$, extension at $72{ }^{\circ} \mathrm{C}$ for $45 \mathrm{sec}$, followed by an extra extension at $72{ }^{\circ} \mathrm{C}$ for $5 \mathrm{~min}$. The BSP products (200 ng) were then cloned into a T-vector (TaKaRa, Japan), and JM109 E. coli competent cells (TaKaRa, Japan) were used for transformation according to the manufacturer's instruction. The sequence of the BSP product was obtained using the ABI model 3730 sequencer. According to the previous study, full methylation at a particular $\mathrm{CpG}$ island was defined as follows: $>60 \%$ of the average bisulfite sequencing signal was "C," whereas partial methylation was $40 \%$ to $60 \%$. "Methylation-positive" was defined as at least 6 of the 12 CpGs within the BSP product showing full or partial methylation [23]. We then detected the methylation status of the CGCG site within the non-canonical E-box motif binding to c-Myc, CACGCG, in other LSCC tissues using BSP-based RFLP by cutting the AccII site. Briefly, $8.5 \mu \mathrm{l}$ of BSP product digestion was initiated by adding $1 \mu \mathrm{l}$ of $10 \mathrm{X}$ Buffer and $0.5 \mu \mathrm{l}$ of $10 \mathrm{U} / \mu \mathrm{l}$ $\operatorname{AccII(TaKaRa,~Japan)~for~} 6$ to 7 hours in a $37^{\circ} \mathrm{C}$ water bath, $5 \mu \mathrm{l}$ of the product was analyzed on $2.5 \%$ agarose gels and the gel image was visualized under a GDS8000 (UVP, USA).

\section{Reverse transcription and real-time quantitative polymerase chain reaction (RQ-PCR)}

After culture in a 6-well plate for $24 \mathrm{~h}$, Hep-2 cells were treated with $4 \mu \mathrm{M}$ 5-aza (Sigma Chemical Co.) for 3 days as previously described [23]. BSP was used again to detect wether Hep-2 cells had been demethylated or not. Total RNA was isolated from Hep-2 cells and Hep-2 cells treated with 5-aza using Trizol reagent (Invitrogen, USA) following the protocol. cDNA was synthesized by reverse transcription using an AMV RNA PCR kit (TaKaRa, Japan). The MYCT1 primers for RQ-PCR were F: 5'- AGGGAGTCCATGGCCAGAAA -3' and R: 5'- ATGAACACAGCCCAAATAAATCCTC -3', which amplified a 105 bp product. GAPDH served as an internal control, which primer sequences were 5'-TGCACCACCAACTGCTTAG -3' and 5'- GACGCAGGGATGATGTTC -3 and were expected to produce a 175 bp DNA fragment. RQ-PCR was carried out on a real-time quantitative PCR instrument (ABI, USA) using a TaKaRa SYBR ${ }^{\circledR}$ Premix Ex Taq ${ }^{\text {mi }}$ kit (TaKaRa, Japan). The 20- $\mu$ l reaction system comprised $400 \mathrm{nM}$ primers, $50 \mathrm{ng}$ cDNA and
$10 \mu \mathrm{l}$ SYBR Premix Ex Taq ${ }^{\mathrm{Tm}}$. The cycling was designed as $95{ }^{\circ} \mathrm{C}$ for $30 \mathrm{~s}, 95{ }^{\circ} \mathrm{C}$ for $5 \mathrm{~s}$, and $60{ }^{\circ} \mathrm{C}$ for $34 \mathrm{~s}$ for 50 cycles. Each sample was measured in 3 separate tubes, and each experiment was run in triplicate. Results of real-time PCR were processed using a $\Delta \Delta \mathrm{Ct}$ method [24]. cDNA from untreated Hep-2 cells was used as calibrator sample.

\section{Plasmid construction and site-directed mutagenesis}

We obtained a novel transcript variation of MYCT1 using 5' RACE, named c-Myc target 1 transcript variant 1(GenBank access number GU997693.1), which indicated the transcript start site of MYCT1 and its variation. Three 5 ' deletion constructs of p852 $(-852 /+12)$, p799 $(-799 /+12)$, and p667 $(-667 /+12)$ of the MYCT1 promoter region were generated by our group, and the results from dual luciferase assays displayed that P852 $(-852 /+12)$ acted as the proximal promoter [12]. Based on the wild-type construct of p852, the P852 mutant was created to replace the E-box B core sequence "CACGCG" with "CAAGGG" (named P852-mutB) using the Gene Tailor site-directed mutagenesis system (Invitrogen, USA) according to the manufacturer's instructions. The primers $\mathrm{Fp}$ (forward primer containing site SacI, 5'-TTTGAGCTCGTGGCCGAGCGCAGT-3'), Rp (reverse primer containing site HindIII, 5'-TTTAAGCTTGTTATTAGCCATAATATCCACAAGA-3'), fm (mutated forward primer, 5'-GTGTGGTGGCAAGGGCCTGTAATCCC-3') and rm (mutated reverse primer, 5'-GGGATTACAGGCCCTTGCCACCACAC-3') were used in site-directed mutagenesis. The $\mathrm{pMD}^{\mathrm{TM}}-\mathrm{T}$ Vector (TaKaRa, Japan) was used for TA cloning and JM109 E. coli competent cells (TaKaRa, Japan) were used for transformation. Colonies were selected and rechecked by electrophoresis. The authenticity of all constructs was confirmed by DNA sequencing on an ABI 3730xl 96-capillary DNA analyzer (ABI, US).

\section{Transient transfection and luciferase assays}

All of the cells used for the subsequent experiments were in log phase. Hep-2 cells were cultured in 24-well plates at a density of $1 \times 10^{5}$ per well overnight in RPMI1640 without FBS and antibiotics. P852, P852-mutB or the empty construct of the luciferase reporter gene $(0.8 \mu \mathrm{g})$ and $16 \mathrm{ng}$ of the internal control plasmid pRLTK were co-transfected into Hep-2 using Lipofectamine $^{\mathrm{Tm}} 2000$ (Invitrogen, USA). The relative luciferase activity was normalized to the TK activity value. At $6 \mathrm{~h}$ after transfection, RPMI-1640 with FBS and antibiotics was added to the cells. The cells were harvested at $48 \mathrm{~h}$ after transfection, and the lysates were analyzed for luciferase activity using the Dual Luciferase Reporter assay (Promega) in a GloMax ${ }^{\text {Th }}$ Microplate Luminometer (Promega). Hep- 2 cells pre-treated with 5 -aza ( $4 \mu \mathrm{M}, 3$ days) were used for P852 to be transfected. The results were 
expressed as relative luciferase activity. The data from triplicates out of five replicates from which the largest and the smallest values were excluded from the analysis are represented as the mean $\pm \mathrm{SD}$.

\section{EMSA (electrophoretic mobility shift assay)}

Two sets of complementary oligonucleotides, F: 5'CGGGTGTGGTGGCACGCGCCTGTAATCCCA -3' and R: 5'-TGGGATTACAGGCGCGTGCCACCACACCCG-3' including the core sequence of CACGCG(-697 to -692), were labeled by Biotin 3' End Labeling Kit (Pierce, USA). EMSA used the Lightshift Chemiluminescent EMSA kit (Pierce, USA) according to the protocols. Nuclear extracts were prepared from Hep-2 cells using a nuclear extract kit (Active Motif, USA) as described in the instructions. The methylated probe was obtained by incubating $20 \mu \mathrm{g}$ of the oligonucleotide with 80 units of M.SssI CpG methylase for two hours at $37^{\circ} \mathrm{C}$ in vitro. Then, the mixture was heated at $65{ }^{\circ} \mathrm{C}$ for $20 \mathrm{~min}$ to inactivate the methylase, purified by polyacrylamide gel electrophoresis, and concentrated with Centricon 3 microconcentrators. The two types of probes $(1 \mathrm{ng})$ were incubated with nuclear extracts $(6 \mu \mathrm{g})$ in protein-DNA binding buffer $(2 \mu \mathrm{l}$ of $10 \mathrm{X}$ binding buffer, $1 \mu \mathrm{l}$ of $50 \%$ Glycerol, $1 \mu \mathrm{l}$ of $\mathrm{MgCl}_{2}, 1 \mu \mathrm{l}$ of poly(dI-dC), and $1 \mu \mathrm{l}$ of $1 \% \mathrm{NP}-40$ ) on ice for $20 \mathrm{~min}$. Competition reactions were pre-performed with a 40/100-fold molar excess of unlabeled, methylated double-stranded competitor DNA. For the supershift reaction, $1 \mu \mathrm{g}$ of each anti-c-Myc antibody (N-262X, Santa Cruz) was preincubated with the nuclear extracts in the absence of poly $(\mathrm{dI} \cdot \mathrm{dC})$ for $20 \mathrm{~min}$ at $4{ }^{\circ} \mathrm{C}$. Subsequently, poly ( $\left.\mathrm{dI} \cdot \mathrm{dC}\right)$ was added and incubated for $5 \mathrm{~min}$, followed by the addition of labeled probe for an additional $20 \mathrm{~min}$. The DNAprotein complexes were separated by electrophoresis on a $6 \%$ native polyacrylamide gel for 1.5 to $2.5 \mathrm{~h}$ at $4{ }^{\circ} \mathrm{C}$ and $100 \mathrm{~V}$, and the complexes were visualized by autoradiography.

\section{Chromatin immunoprecipitation assay (ChIP)}

ChIP assay were performed as previously described [12]. Hep-2 cells were treated with 5-aza in accordance with RQ-PCR. Cells were fixed by the addition of $1 \%$ formaldehyde in growth medium for $10 \mathrm{~min}$ at $37{ }^{\circ} \mathrm{C}$. After washed with ice-cold PBS, cells were lysed with lysis buffer containing protease inhibitors and chromatin from

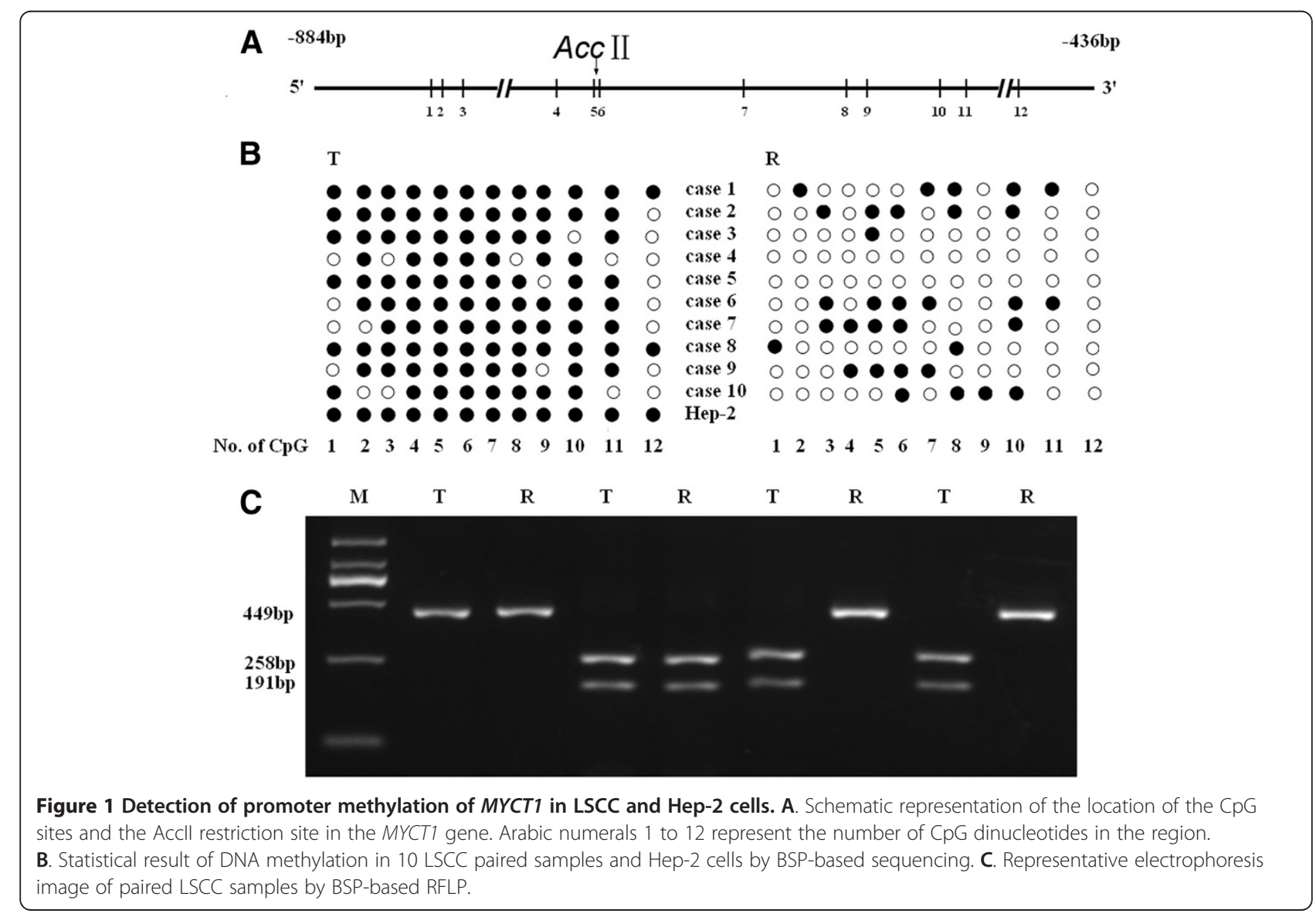


cells was sheared by sonicator. Half of DNA fragments was saved as input DNA. The rest was incubated with anti-c-Myc antibody (N-262X, Santa Cruz), and immunoprecipitated by protein A/G plus-agarose (Santa Cruz, USA) which was eluted and extracted with phenolchloroform, whose concentrations were measured with a spectrophotometer. The input and immunoprecipitated DNA were used as templates for Real Time PCR performed with MYCT1 core promoter-specific primer amplifying the second $\mathrm{c}-\mathrm{Myc}$ binding regions (c-Myc B, F:5'-GAGGTCAGGCCTAGTTCATG-3', and R:5'-CTTAGT CTCGCTCTGTCGC-3') in accordance with RQ-PCR except the difference of 40 cycles. The percentage of MYCT1 promoter that was bound with c-Myc B was calculated based on the differences between $\mathrm{Ct}$ values for input and DNA samples immunoprecipitated from Hep-2 cells treated or untreated with 5-zaz [25].

\section{Statistical analysis}

All statistical analyses were performed using the SPSS 13.0 software. The chi-squared test was utilized to analyze the relationship between methylation and clinicopathological characteristics. The comparisons mRAN level and percentage of MYCT1 promoter occupation were carried out using one-way analysis of variance (ANOVA) and the Students-Newman-Keuls (SNK) method were employed for group comparison. $P$ values of less than 0.05 were considered to be statistically significant.

\section{Results}

\section{Methylation status of the MYCT1 promoter region}

Twelve CpG sites are illustrated in the sequence of the PCR product (Figure 1A). BSP-based sequencing showed that 11 of the $12 \mathrm{CpG}$ sites in the MYCT1 gene promoter displayed full methylation except site 12 in Hep-2 cells and LSCC, which indicated that the MYCT1 promoter was methylation-positive (Figure 1B). Both BSPbased sequencing and RFLP results (Figure $1 C$ ) at the site CGCG (-695 to -692$)$ revealed that 46 of $73(63 \%)$ cases of LSCC showed methylation in cancer tissues and no methylation in paired normal tissue, 13 cases showed methylation in both cancer and paired normal tissues, and 14 cases showed no methylation in either cancer or paired normal tissues. These data indicated that a significant difference in MYCT1 promoter methylation status exists between cancer and paired normal tissues (Table 1). Tumors classified as undifferentiated or poorly differentiated compared with those classified as well differentiated showed significantly higher methylation. The MYCT1 hypermethylation in LSCC was not significantly associated with age, gender, TNM staging, lymph node metastasis, distant metastasis or clinical stage of the patients (Table1).

\section{Effects of treatment with epigenetic-modifying agents on MYCT1 mRNA expression}

To investigate the possible epigenetic regulation of MYCT1 expression, RQ-PCR analysis was performed in Hep-2 cells that did or did not be treated with a DNA demethylating agent, 5-aza. BSP-based sequencing revealed that the MYCT1 gene promoter was demethylated in Hep-2 cells by the treatment of 5 -aza (Figure 2A). Following 5-aza treatment of Hep-2 cells, MYCT1 mRNA expression increased, which showed statistically significant differences among the two groups $(\mathrm{p}<0.01)$ (Figure 2B). This result suggested that DNA methylation modification down-regulated MYCT1 gene expression.

Table 1 Correlation of CGCG (-695 -692) methylaton with case characteristics

\begin{tabular}{|c|c|c|c|c|}
\hline & $\begin{array}{l}\text { Case } \\
\text { (n) }\end{array}$ & $\begin{array}{l}\text { Positve } \\
\text { (n) }\end{array}$ & $\begin{array}{l}\text { Negative } \\
\text { (n) }\end{array}$ & $P$ \\
\hline \multicolumn{5}{|l|}{ Sample } \\
\hline Cancer tissue & 73 & 59 & 14 & \multirow[t]{2}{*}{$P<0.01$} \\
\hline Paired normal tissue & 73 & 13 & 60 & \\
\hline \multicolumn{5}{|l|}{ Age at surgery } \\
\hline$<60$ & 35 & 28 & 7 & \multirow[t]{2}{*}{0.864} \\
\hline$>60$ & 38 & 31 & 7 & \\
\hline \multicolumn{5}{|l|}{ Gender } \\
\hline Male & 58 & 47 & 11 & \multirow[t]{2}{*}{0.928} \\
\hline Female & 15 & 12 & 3 & \\
\hline \multicolumn{5}{|l|}{ Histological classification } \\
\hline Poorly differentiated & 49 & 46 & 3 & \multirow[t]{2}{*}{$P<0.01$} \\
\hline Well differentiated & 24 & 13 & 11 & \\
\hline \multicolumn{5}{|l|}{ T classification } \\
\hline $\mathrm{T} 1$ & 13 & 10 & 3 & \multirow[t]{4}{*}{0.980} \\
\hline $\mathrm{T} 2$ & 26 & 21 & 5 & \\
\hline T3 & 28 & 23 & 5 & \\
\hline $\mathrm{T} 4$ & 6 & 5 & 1 & \\
\hline \multicolumn{5}{|l|}{ Lymph node metastasis } \\
\hline Negative & 55 & 44 & 11 & \multirow[t]{2}{*}{0.755} \\
\hline Positive & 18 & 15 & 3 & \\
\hline \multicolumn{5}{|l|}{ Distant metastasis } \\
\hline Negative & 69 & 56 & 13 & \multirow[t]{2}{*}{0.761} \\
\hline Positive & 4 & 3 & 1 & \\
\hline \multicolumn{5}{|l|}{ Clinical stage } \\
\hline 1 & 13 & 9 & 4 & \multirow[t]{4}{*}{0.533} \\
\hline$\|$ & 22 & 17 & 5 & \\
\hline III & 30 & 26 & 4 & \\
\hline IV & 8 & 7 & 1 & \\
\hline
\end{tabular}




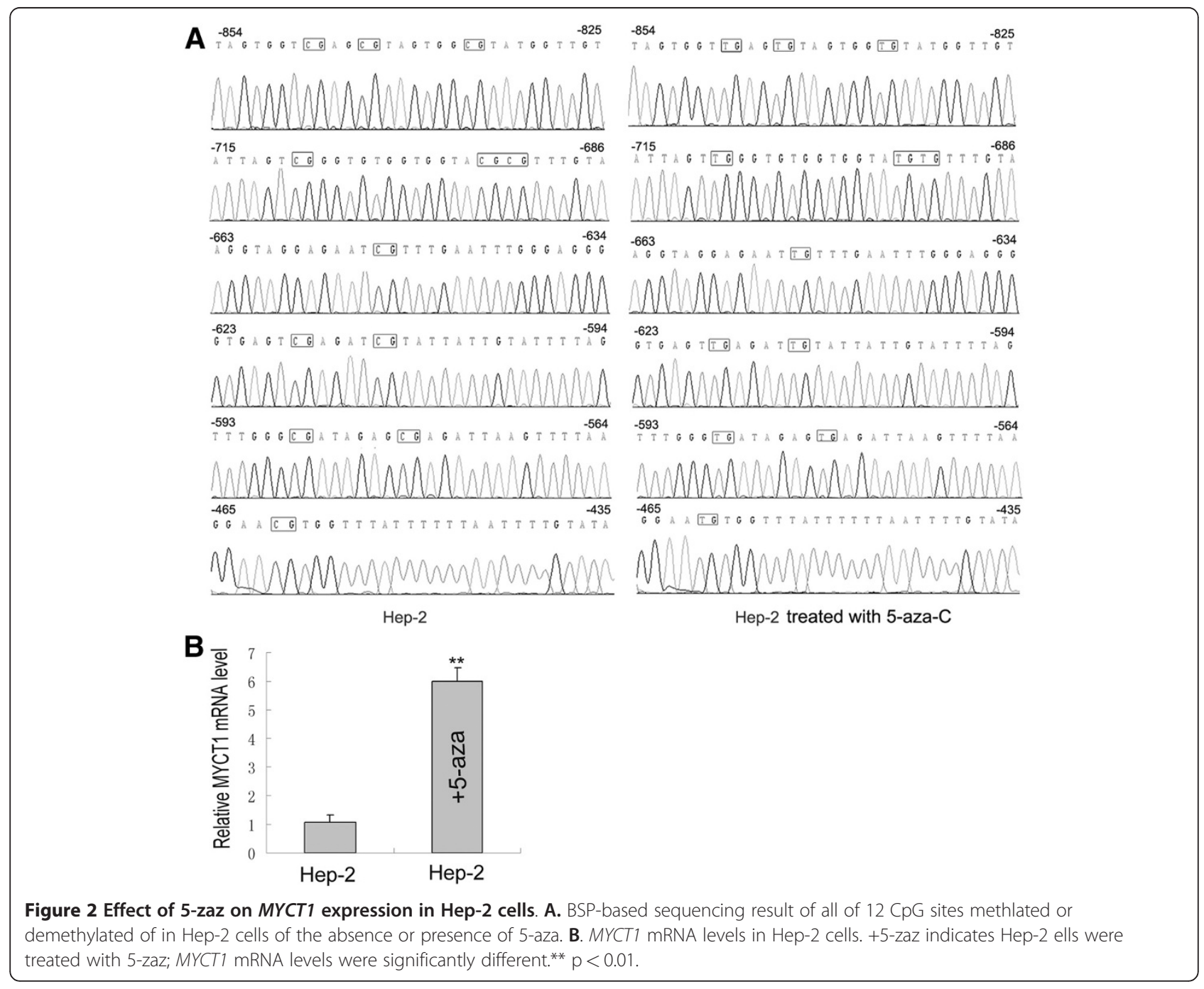

The site CGCG ( -695 to -692$)$ is involved in MYCT1 promotion/enhancement

The mutated sites of P852-mutB are illustrated in Figure 3A. The promoter region between $-852 \mathrm{bp}$ and $-667 \mathrm{bp}$ was basal for the transcriptional activity, in which the putative core promoter sequences (-730 bp to $-681 \mathrm{bp}$ ) owned only one DNA motif of regulatory elements, a noncanonical E-box "CACGCG" [7,12]. To determine whether the CGCG site ( -695 to -692$)$ affected the promoter activity of $M Y C T 1$, we created a plasmid containing mutations in the CGCG site (-695 to -692), named P852-mutB, based on the wild-type P852 $(-852$ to +12$)$. The results from a transient transfection assay showed that the P852 construct expressed a high level of luciferase activity in Hep-2 cells treated with 5-aza, indicating that some important element in the construct up-regulates $M Y C T 1$ expression. The luciferase activities in P852-mutB transfectants were significantly reduced compared with wild-type P852, which suggests that this site plays an important role in regulating MYCT1 expression (Figure 3B).

\section{Methylation interferes with the binding between the MYCT1 promoter and c-myc}

EMSA confirmed the specific binding by c-Myc antibody abrogating the band gel shift and the specific shift band was faint when the biotin-labeled probe methylated using M.SssI methylase mixed with nuclear proteins from Hep2 cells (Lane 2, 5 in Figure 4A). In the competition reaction, the specific band was not effectively competed when an excess amount of free probes methylated were added before the binding of nuclear proteins (Lane3,4 in Figure 4A). The effect of promoter methylation on the interaction between C-Myc and MYCT1 core promoter was further confirmed by ChIP assay. Using the primer to amplify $\mathrm{C}-\mathrm{Myc} \mathrm{B}$ binding regions of MYCT1 promoter, we observed different DNA levels based on the precipitate by c-Myc antibody from Hep2 


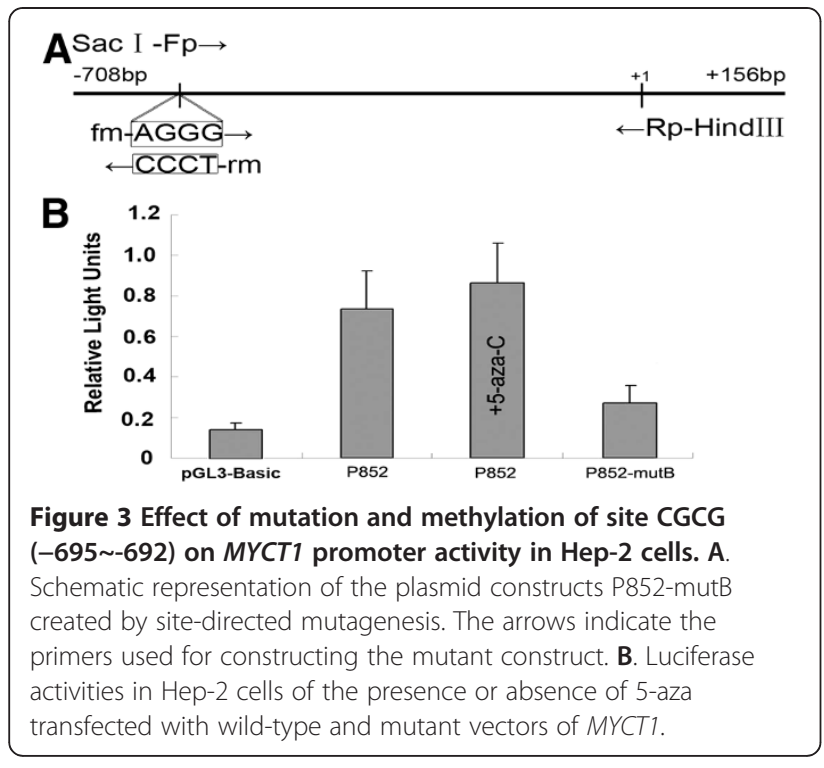

cells and Hep2 cells of 5-aza treatment (Figure 4B). The quantities of DNA precipitated by c-Myc antibody from the treated Hep2 cells increased significantly $(\mathrm{p}<0.01)$. These data suggest that the methylation in the core sequence including the CGCG site (-695 to -692$)$ interferes with the specific binding of c-Myc.

\section{Discussion}

Multiple genetic and epigenetic alterations in tumor suppressor genes and oncogenes are important in carcinogenesis [26-28]. Therefore, identifying the corresponding genes and exploring the regulatory mechanisms involved in tumor progression have become critical issues. DNA methylation is one of the main mechanisms of epigenetics. Methylation in gene promoter regions has been well established to contribute to the inactivation of tumor suppressors [29-31].

Our previous study revealed that low MYCT1 expression is found in LSCC and that MYCT1 can inhibit cell growth and promote cell apoptosis, which suggests that MYCT1 may be a candidate TSG [11]. Methylation of CpG islands has been expected in the MYCT1 promoter region. The present study focused on the epigenetic alterations leading to transcriptional down-regulation of MYCT1, thereby opening a new avenue to understand the molecular pathways in laryngeal cancer and to develop potential therapeutics against laryngeal cancer.

In this study, 12 potential methylated sites in the MYCT1 promoter region were predicted in silico, and hypermethylation was observed in 10 LSCC tumor samples and the Hep2 cancer cells by BSP-based sequencing. Among these methylated sites, the sequence CGCG (-695 to -692$)$ is localized in a non-canonical E-box motif, CACGCG, which specifically binds to the transcription factor c-Myc [12]. We asked whether methylation of the potential c-Myc

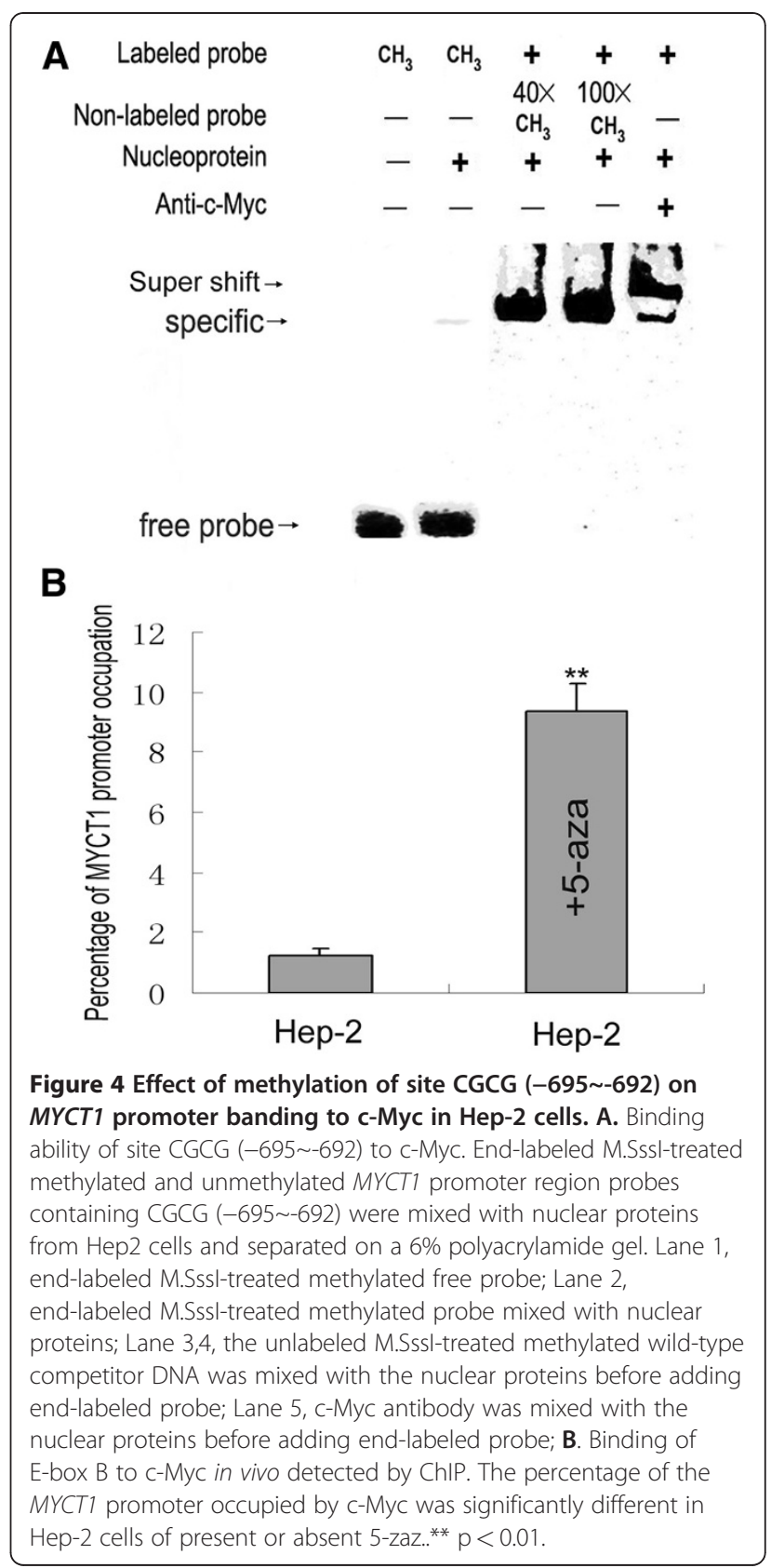

binding site plays a role in the regulation of MYCT1. We further explored the methylation status of CGCG (-695 to -692 ) using BSP-based RFLP in the subsequent 63 tumor samples. In total, $80.8 \%$ of the tumor samples showed methylation at this site compared to $17.8 \%$ in paired mucosa, which displayed a significant difference. We observed that methylation of the CGCG site ( -695 to -692) significantly correlated with cancer cell differentiation but did not correlate with age, gender and TNM staging, suggesting that MYCT1 methylation could inhibit cancer cell differentiation. In our group, Fu et al. found that the average transcription levels of MYCT1/ 
Table 2 Difference between CGCG (-695 -692) methylation and mRNA level of MYCT1 in LSCC

\begin{tabular}{llllr}
\hline & $\begin{array}{l}\text { Methylation } \\
\text { status }\end{array}$ & $\begin{array}{l}\text { Methylation } \\
\text { number (\%) }\end{array}$ & $\begin{array}{l}\text { mRNA level } \text { MYCT1/ } \\
\text { Beta actin (ratio) }\end{array}$ & t value \\
\hline Cancer tissue & + & 59 & $0.31 \pm 0.09$ & 18.620 \\
& - & 14 & $0.88 \pm 0.15$ & $P<0.01$ \\
Paired tissue & + & 13 & $0.25 \pm 0.11$ & 14.289 \\
& - & 60 & $0.96 \pm 0.17$ & $P<0.01$ \\
\hline
\end{tabular}

Beta-actin were 0.42 and 0.83 in 73 cases of laryngeal cancer tissue and paired normal tissue, respectively [12]. We then analyzed the relationship between the methylation status of site CGCG (-695 -692) and the transcription levels of MYCT1. An inverse correlation between the methylation status of this site and the MYCT1 mRNA level was pronounced and significant in either LSCC tissues or paired tissue, which implies that promoter methylation inhibits the transcription of MYCT1 (Table 2).

To confirm that the aberrant methylation of MYCT1 induced transcriptional down-regulation, we compared its mRNA levels in laryngeal carcinoma Hep2 cells to Hep2 cells treated with the inhibitor of the methylase enzyme 5-aza. We found the MYCT1 mRNA levels of MYCT1 were markedly raised $(\mathrm{p}<0.01)$ after the treatment, suggesting that the gene MYCT1 was suppressed by epigenetic modification. The mechanism were found in certain tumor suppression genes of cancer cell lines [32,33].

To explore how and why methylation of the CGCG site ( -695 to -692$)$ leads to low transcription of MYCT1, we constructed the wild-type and mutant-type expressing vectors P852 $(-852 /+12)$ and P852-mutB. The results from luciferase assays revealed that the promoter sequence including the non-canonical E-box motif CACGCG (-697 to -692$)$ can have promoter activity and that the point mutation of cytosine at -695 and -693 impaired the activity of luciferase, suggesting that aberrations, including methylation, on this site can affect the promoter activity of MYCT1. Interestingly, with the action of 5-aza, P852 owned the higher promoter activity. In further investigation, a CGCG-containing probe was used in EMSA to identify its binding to c-Myc. The result confirmed that the non-canonical E-box motif CACGCG (-697 to -692$)$ could bind to the nuclear extracts, the specific binding band lessened significantly because the probe was methylated, while normal labeled probes could not be competed off by the unlabeled methylated wild-type probe. In addition, we observed DNA demethylation was associated with a rising occupancy percentage of the promoter by c-Myc in ChIP assay. These data suggest that methylation around the CGCG (-695 to -692 ) in the MYCT1 promoter might interfere with the binding of $\mathrm{c}-\mathrm{Myc}$ to this motif. According to a previous report, c-Myc controls the methylation status of the core promoter of target genes through a pathway in which DNA methyltransferase 3A is recruited depending on the cellular context [33]. In addition, the cooperation of c-Myc and other proteins participates in the stable methylation-dependent repression of downstream genes [34]. Consistent with our study, c-Myc could mediate transcriptional silencing through DNA methylation in cell differentiation in cancer $[35,36]$.

5-aza was used to select genes for early detection and prognostic biomarkers of head and neck squamous cell carcinoma (HNSCC) [37]. Recently, 5-aza combined with other therapeutics including irradiation and chemotherapy has been considered and tried in the treatment of LSCC [38,39].

\section{Conclusions}

This report is the first to describe transcriptional downregulation of the MYCT1 gene through epigenetic pathways in malignant tumors. We conclude that MYCT1 is down-regulated by promoter hypermethylation. Our data further indicate that the transcription factor $\mathrm{c}-\mathrm{Myc}$ participates in the regulation of MYCT1 transcription and that DNA methylation interferes with the binding of c-Myc to the MYCT1 promoter region. This result provides a clue for selection of LSCC patients in 5-azamediated treatment, but how to solve it is also a problem in further study.

Competing interests

The authors declare that they have no competing interest.

\section{Authors' contribution}

MY performed experiments and WL drafted the manuscript. $Y-Y L, S F, G-B Q$, K-L S and W-N F participated in the design of the study and statistics of data. All authors have read and approved the final manuscript.

\section{Acknowledgements}

This work was supported by the National Natural Science Foundation of China (81102057 and 81172577) and the Natural Science Foundation of Liaoning Province (20092110).

\section{Author details}

'Department of Medical Genetics, China Medical University, Shenyang 110001, P.R. China. ${ }^{2}$ Shenyang Police-dog Technology School of Ministry of Public Security, Shenyang 110034, P.R. China. ${ }^{3}$ ENT Department, the First Affiliated Hospital of China Medical University, Shenyang 110001, P.R. China. ${ }^{4}$ Department of Laboratory Medicine, No. 202 Hospital of PLA, Shenyang 110003, P.R. China.

Received: 1 March 2012 Accepted: 6 June 2012

Published: 6 June 2012 


\section{References}

1. Cattaruzza MS, Maisonneuve P, Boyle P: Epidemiology of laryngeal cancer. Eur J Cancer B Oral Oncol 1996, 32B:293-305.

2. Chen $K$, Song $F$, He M, et al: Trends in head and neck cancer incidence in Tianjin, China, between 1981 and 2002. Head Neck 2009, 31:175-182.

3. Morshed K, Polz-Dacewicz M, Szymanski M, et al: Short-fragment PCR assay for highly sensitive broad-spectrum detection of human papillomaviruses in laryngeal squamous cell carcinoma and normal mucosa: clinico-pathological evaluation. Eur Arch Otorhinolaryngol 2008, 265(Suppl 1):S89-S96.

4. Ma XJ, Pan XL, Lv ZH, et al: Therapeutic influence on circulating and monocyte-derived dendritic cells in laryngeal squamous cell carcinoma patients. Acta Otolaryngol 2009, 129:84-91.

5. Kada S, Hirano S, Tateya I, et al: Ten years single institutional experience of treatment for advanced laryngeal cancer in Kyoto University. Acta Otolaryngol Supp/ 2010, (563):68-73.

6. Marioni G, Marchese-Ragona R, Cartei G, et al: Current opinion in diagnosis and treatment of laryngeal carcinoma. Cancer Treat Rev 2006, 32:504-515.

7. Qiu G, Xu Z, Huang D, et al: Cloning and characterization of MTLC, a novel gene in 6q25. Zhonghua Yi Xue Yi Chuan Xue Za Zhi 2003, 20:94-97.

8. Rogulski KR, Cohen DE, Corcoran DL, et al: Deregulation of common genes by c-Myc and its direct target, MT-MC1. Proc Natl Acad Sci USA 2005, 102:18968-18973.

9. Reymann S, Borlak J: Transcription profiling of lung adenocarcinomas of c-myc-transgenic mice: identification of the c-myc regulatory gene network. BMC Syst Bio/ 2008, 2:46.

10. Li Y, Lu J, Prochownik EV: c-Myc-mediated genomic instability proceeds via a megakaryocytic endomitosis pathway involving Gp1balpha. Proc Natl Acad Sci USA 2007, 104:3490-3495.

11. Qiu GB, Gong LG, Hao DM, et al: Expression of MTLC gene in gastric carcinoma. World J Gastroenterol 2003, 9:2160-2163.

12. Fu S, Guo Y, Chen H, et al: MYCT1-TV, A Novel MYCT1 Transcript, Is Regulated by c-Myc and May Participate in Laryngeal Carcinogenesis. PLOS One 2011, 6:e25648

13. Dang CV, O'Donnell KA, Zeller Kl, et al: The c-Myc target gene network. Semin Cancer Biol 2006, 16:253-264.

14. Kim J, Lee JH, lyer VR: Global identification of Myc target genes reveals its direct role in mitochondrial biogenesis and its E-box usage in vivo. PLoS One 2008, 3:e1798.

15. Kuznetsov VA, Singh $O$, Jenjaroenpun P: Statistics of protein-DNA binding and the total number of binding sites for a transcription factor in the mammalian genome. BMC Genomics 2010, 11(Suppl 1):S12.

16. Haggerty TJ, Zeller Kl, Osthus RC, et al: A strategy for identifying transcription factor binding sites reveals two classes of genomic c-Myc target sites. Proc Natl Acad Sci USA 2003, 100:5313-5318.

17. Blackwood EM, Eisenman RN: Max: a helix-loop-helix zipper protein that forms a sequence-specific DNA-binding complex with Myc. Science 1991, 251:1211-1217.

18. Si J, Yu X, Zhang Y, DeWille JW: Myc interacts with Max and Miz1 to repress C/EBPdelta promoter activity and gene expression. Mol Cancer 2010, 9:92

19. Chen PY, Chang WS, Lai YK, et al: c-Myc regulates the coordinated transcription of brain disease-related PDCD10-SERPINI1 bidirectional gene pair. Mol Cell Neurosci 2009, 42:23-32.

20. Perini $G$, Diolaiti $D$, Porro $A$, et al: In vivo transcriptional regulation of $\mathrm{N}-\mathrm{Myc}$ target genes is controlled by E-box methylation. Proc Natl Acad Sci USA 2005, 102:12117-12122.

21. Sharp TV, Al-Attar A, Foxler DE, et al: The chromosome 3p21.3-encoded gene, LIMD1, is a critical tumor suppressor involved in human lung cancer development. Proc Natl Acad Sci USA 2008, 105:19932-19937.

22. Furuta T, Shuto T, Shimasaki S, et al: DNA demethylation-dependent enhancement of toll-like receptor-2 gene expression in cystic fibrosis epithelial cells involves SP1-activated transcription. BMC Mol Biol 2008, 9:39.

23. Wang J, Chen H, Fu S, et al: The involvement of CHD5 hypermethylation in laryngeal squamous cell carcinoma. Oral Oncol 2011, 47:601-608.

24. Oliveira MS, Skinner F, Arshadmansab MF, et al: Altered expression and function of small-conductance (SK) $\mathrm{Ca}(2+)$-activated K+channels in pilocarpine-treated epileptic rats. Brain Res 2010, 1348:187-199.

25. Rawłuszko AA, Horbacka K, Krokowicz $P$, et al: Decreased expression of $17 \beta$-hydroxysteroid dehydrogenase type 1 is associated with DNA hypermethylation in colorectal cancer located in the proximal colon. BMC Cancer 2011, 11:522

26. Mullighan CG, Zhang J, Kasper $\mathrm{LH}$, et al: CREBBP mutations in relapsed acute lymphoblastic leukaemia. Nature 2011, 471:235-239.

27. Lahousse SA, Hoenerhoff M, Collins J, et al: Gene expression and mutation assessment provide clues of genetic and epigenetic mechanisms in liver tumors of oxazepam-exposed mice. Vet Pathol 2011, 48:875-884.

28. Arai $E$, Kanai $Y$ : Genetic and epigenetic alterations during renal carcinogenesis. Int J Clin Exp Pathol 2010, 4:58-73.

29. Bell A, Bell D, Weber RS, et al: CpG Island Methylation Profiling in Human Salivary Gland Adenoid Cystic Carcinoma. Cancer 2011, 117:2898-2909.

30. Uhm KO, Lee ES, Lee YM, et al: Aberrant promoter CpG islands methylation of tumor suppressor genes in cholangiocarcinoma. Oncol Res 2008, 17:151-157.

31. Wu X, Liu W, Tian Y, et al: Aberrant methylation of death-associated protein kinase $1 \mathrm{CpG}$ islands in myelodysplastic syndromes. Acta Haematol 2011, 125:179-185.

32. Li W, Li X, Wang W, et al: NOR1 is an HSF1- and NRF1-regulated putative tumor suppressor inactivated by promoter hypermethylation in nasopharyngeal carcinoma. Carcinogenesis 2011, 32:1305-1314.

33. Du C, Huang T, Sun D, et al: $\mathrm{CDH} 4$ as a novel putative tumor suppressor gene epigenetically silenced by promoter hypermethylation in nasopharyngeal carcinoma. Cancer Lett 2011, 309:54-61.

34. Hervouet $E$, Vallette FM, Cartron PF: Dnmt3/transcription factor interactions as crucial players in targeted DNA methylation. Epigenetics 2009, 4:487-499.

35. Weng W, Yang Q, Huang M, et al: c-Myc inhibits TP53INP1 expression via promoter methylation in esophageal carcinoma. Biochem Biophys Res Commun 2011, 405:278-284.

36. Licchesi JD, Van Neste L, Tiwari VK, et al: Transcriptional regulation of Wnt inhibitory factor-1 by Miz-1/c-Myc. Oncogene 2010, 29:5923-5934.

37. Calmon MF, Rodrigues RV, Kaneto CM, et al: Epigenetic silencing of CRABP2 and MX1 in head and neck tumors. Neoplasia 2009, 11:1329-1339.

38. Brieger J, Mann SA, Pongsapich W, et al: Pharmacological genome demethylation increases radiosensitivity of head and neck squamous carcinoma cells. Int J Mol Med 2012, 29:505-509.

39. Bauman J, Verschraegen C, Belinsky S, et al: A phase I study of 5 -azacytidine and erlotinib in advanced solid tumor malignancies. Cancer Chemother Pharmacol 2012, 69(2):547-54.

doi:10.1186/1471-2407-12-219

Cite this article as: Yang et al:: Promoter hypermethylation-induced transcriptional down-regulation of the gene MYCT1 in laryngeal squamous cell carcinoma. BMC Cancer 2012 12:219.

\section{Submit your next manuscript to BioMed Central and take full advantage of:}

- Convenient online submission

- Thorough peer review

- No space constraints or color figure charges

- Immediate publication on acceptance

- Inclusion in PubMed, CAS, Scopus and Google Scholar

- Research which is freely available for redistribution 